\title{
Role of early and late oestrogenic effects on implantation in the mouse
}

\author{
Y. M. Huet and S. K. Dey \\ Departments of Physiology and Obstetrics \& Gynecology, Ralph L. Smith Research Center, \\ University of Kansas Medical Center, Kansas City, KS 66103, U.S.A.
}

\begin{abstract}
Summary. Oestrogen action in the uterus is expressed in an early phase (Phase I) and a late phase (Phase II). The role of this biphasic oestrogen action in implantation is not clear. To determine the relative importance of Phase I and II responses, triphenylethylene compounds (CI-628, LY-117018, nafoxidine, clomiphene citrate and tamoxifen) and oestrogens (oestriol and oestradiol-17 $\beta$ ) were used in a physiologically relevant experimental system for studying implantation. All compounds elicited uterine water imbibition to various degrees in ovariectomized-progesterone-treated mice at $6 \mathrm{~h}$ (Phase I response) and their effectiveness in inducing implantation in delayed implanting mice correlated with their respective potency to increase uterine wet weight. This suggests that Phase I might be an essential component of oestrogen action in implantation and that the efficiency of a compound to elicit a Phase I response might serve as a predictive indicator of its potential action on implantation.
\end{abstract}

\section{Introduction}

Ovarian progesterone and oestrogen are required for implantation in the mouse. Ovariectomy before the presumed oestrogen surge on Day 4 of pregnancy results in dormancy of the blastocyst and delayed implantation (Yoshinaga \& Adams, 1966; McLaren, 1973; McCormack \& Greenwald, 1974). Implantation can be initiated, however, if the animals are pretreated with progesterone followed by a single injection of oestrogen (Yoshinaga \& Adams, 1966; McLaren, 1973). This model has been shown to be very sensitive for testing oestrogenicity of compounds and determining their mechanism of action. In the uterus, oestrogen action has been characterized as an early phase (Phase I) and a late phase (Phase II) (Astwood, 1939; Kirkland et al., 1977; Harris \& Gorski, 1978; Galand et al., 1983). The role of this biphasic oestrogen action in implantation remains undefined.

Phase I effects occur within $6 \mathrm{~h}$ and fluid imbibition is one of its predominant characteristics. Phase II or true growth phase is characterized by hyperplasia and hypertrophy and occurs within 18-30 h (Kirkland et al., 1977; Harris \& Gorski, 1978; Galand et al., 1983). Our objectives were to search for compounds that would show either Phase I, Phase II or both phases of oestrogenic responses and to determine their relative importance in the initiation of implantation. In ovariectomized animals, oestradiol-17 $\beta$ expresses characteristics of both phases, whereas oestriol, when administered as a single injection, induces mainly Phase I responses (Clark et al., 1977; Kirkland et al., 1977; Harris \& Gorski, 1978; Galand et al., 1983). Triphenylethylene compounds are generally considered to be antioestrogens because of their capacity to antagonize oestrogen responses in the target organs. However, these compounds possess weak inherent oestrogenicity and can manifest partial agonistic responses in the uterus (Katzenellenbogen \& Ferguson, 1975; Gardner et al., 1978; Black \& Goode, 1980; Clark \& Markaverich, 1982). Although as agonists they show some uterine growth, it has not been documented whether they can induce biphasic responses. We have studied different kinds of oestrogens (oestriol and oestradiol-17 $\beta$ ) and triphenylethylene compounds 
(CI-628, nafoxidine, tamoxifen, LY-117018, clomiphene citrate) to determine their Phase I and Phase II responses in the uterus of ovariectomized-progesterone-treated mice and their effects on implantation in delayed implanting mice.

\section{Materials and Methods}

Charles River (CD-1) female mice (48 days old, 20-25g) were used. To determine Phase I and Phase II uterine responses, we used widely accepted fluid imbibition at $6 \mathrm{~h}$ and dry weight increases at $24 \mathrm{~h}$, respectively. Mice were ovariectomized without regard to the stages of the oestrous cycle. After 3 days, they were treated subcutaneously (s.c.) with progesterone ( $2 \mathrm{mg} / 0 \cdot 1 \mathrm{ml}$ sesame seed oil/mouse: Sigma Chemical Co., St Louis, MO) for 4 Jays. On the last day of progesterone treatment, they were given a single injection of a test compound. Uterine wet and dry weights were recorded at $6 \mathrm{~h}$ and $24 \mathrm{~h}$, respectively. CI-628 (Warner-Lambert/Parke-Davis, Ann Arbor, MI), tamoxifen (Stuart Pharmaceuticals, Wilmington, DE), and clomiphene citrate (Richardson-Merrell, Inc., Cincinnati, $\mathrm{OH}$ ) were dissolved in $0.15 \mathrm{M}-\mathrm{NaCl}$ solution and injected intraperitoneally (i.p.). Oestradiol-17ß (Sigma), oestriol (Sigma) and LY-117018 (Eli Lilly, Indianapolis, IN) were dissolved in oil and injected s.c. Nafoxidine (Upjohn, Kalamazoo, MI) was dissolved in propylene glycol and injected i.p. To study the effect of these agents on the induction of implantation, mice were ovariectomized on the morning of Day 4 of pregnancy (Day $1=$ vaginal plug) and injected daily (s.c.) with $2.0 \mathrm{mg}$ progesterone dissolved in $0.1 \mathrm{ml}$ sesame seed oil, beginning on Day 5 , for 5 days. On the 4 th day of progesterone treatment (Day 8 of pregnancy), they were given a single injection of oestradiol, oestriol or triphenylethylene compounds. To determine whether triphenylethylene compounds were able to interfere with oestradiol-induced implantation in delayed implanting mice, Cl-628 or LY-117018 was injected $30 \mathrm{~min}$ before, or LY-117018 was injected $30 \mathrm{~min}$ before and $4 \mathrm{~h}$ after administration of oestradiol-173. Implantation sites were determined at $48 \mathrm{~h}$ by an i.v. injection of $0 \cdot 1 \mathrm{ml}$ 1\% Chicago Blue B (Sigma) $5 \mathrm{~min}$ before the mice were killed (Psychoyos, 1973). Discrete blue bands around the uterus indicated implantation sites. Uteri of animals without implantation sites were flushed with $500 \mu \mathrm{l} 0.15 \mathrm{M}-\mathrm{NaCl}$ solution and the flushings were examined under a dissecting microscope for the presence of blastocysts. Animals without implantation sites or blastocysts were excluded from the experiment.

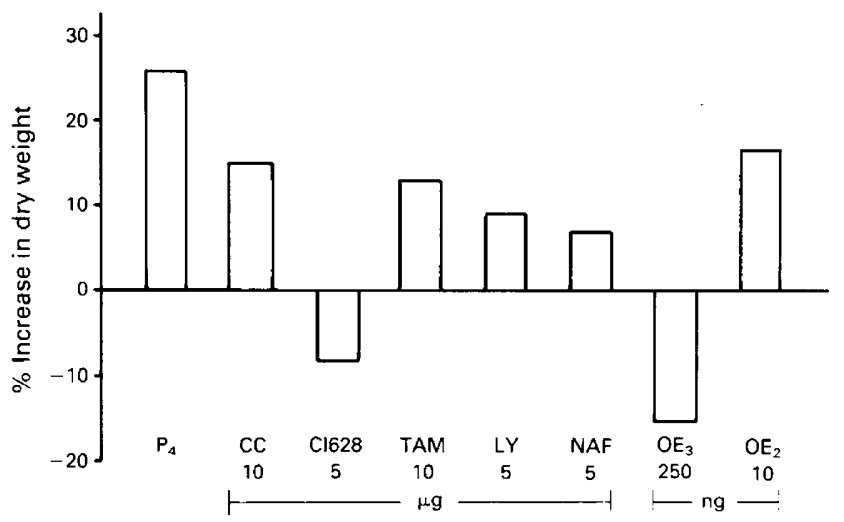

Fig. 1. Effects of oestrogens and triphenylethylene compounds on uterine dry weights at $24 \mathrm{~h}$ (a Phase II response). Percentage increase in dry weight at $24 \mathrm{~h}$ was calculated from the formula: [(dry weight at $24 \mathrm{~h}-$ dry weight at $6 \mathrm{~h}) /$ dry weight at $6 \mathrm{~h}] \times 100$. Dry weights at $24 \mathrm{~h}$ were derived from 4-6 animals while 5-8 animals contributed to dry weights at $6 \mathrm{~h}$ in each treatment group. All animals received progesterone $\left(2 \mathrm{mg} /\right.$ mouse/day). Progesterone $\left(\mathrm{P}_{4}\right)$, clomiphene citrate (CC), tamoxifen (TAM), LY-117018 (LY), nafoxidine (NAF), oestriol ( $\mathrm{OE}_{3}$ ), oestradiol$17 \beta\left(\mathrm{OE}_{2}\right)$.

\section{Results}

None of the oestrogens or triphenylethylene compounds produced increases in uterine dry weights at $24 \mathrm{~h}$ (a Phase II response) but rather decreased it when compared to progesterone treatment only (Fig. 1). In fact, oestriol and CI-628 showed the most negative influence on this parameter. Of all of 


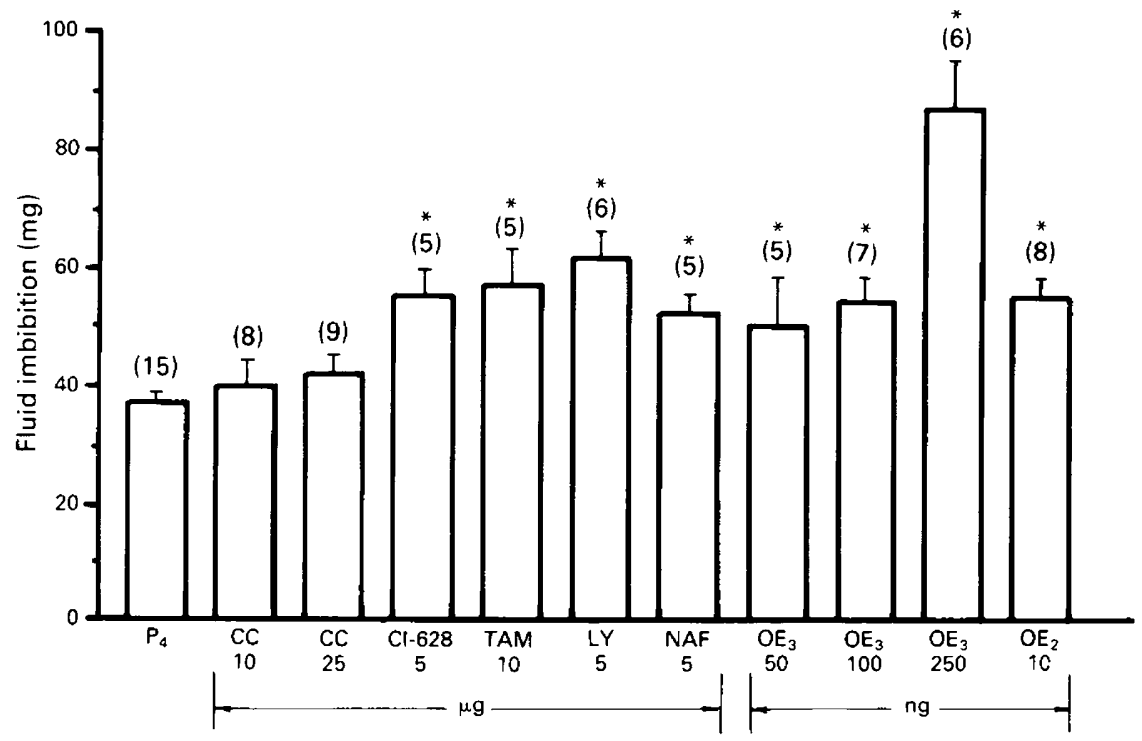

Fig. 2. Effects of oestrogens and triphenylethylene compounds on uterine fluid imbibition at $6 \mathrm{~h}$ (a Phase I response). Fluid imbibition is defined as the uterine wet weight minus the dry weight at 6 h. Results shown are means $\left( \pm\right.$ s.e.m.) for the no. of animals in parentheses. ${ }^{*} P<0.05$ compared to the progesterone treated values (ANOVA). All animals received progesterone ( $2 \mathrm{mg} / \mathrm{mouse} /$ day). Abbreviations are as in Fig. 1.

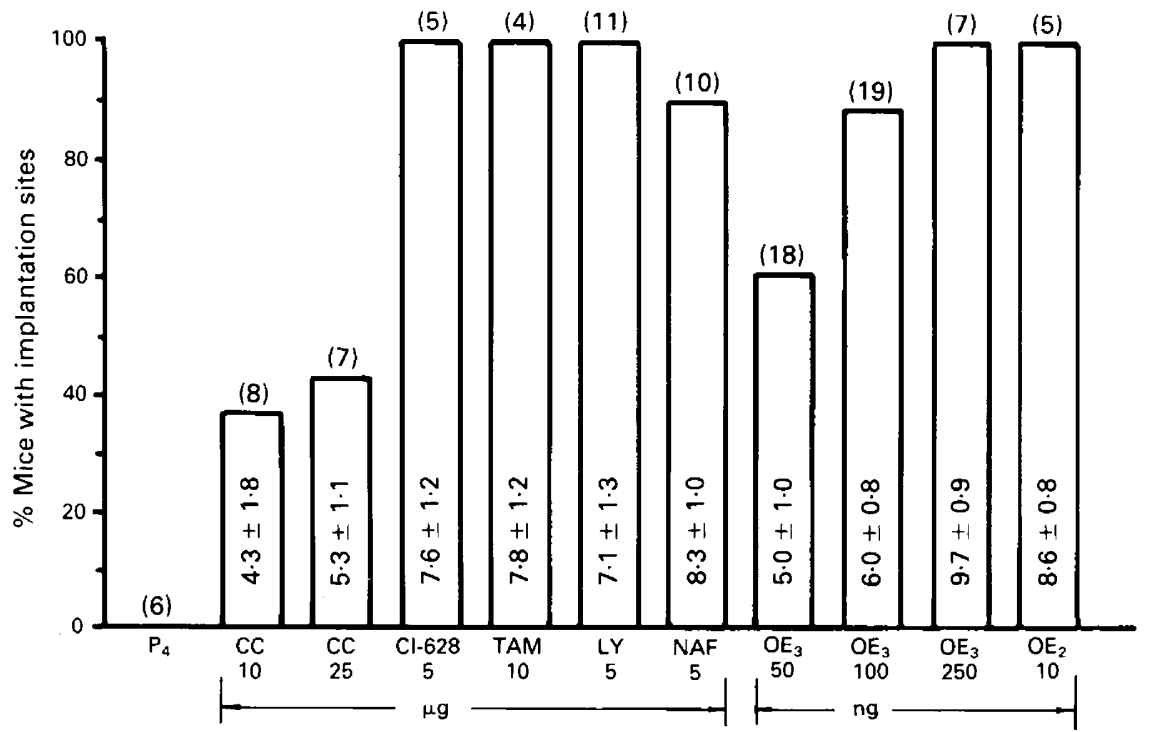

Fig. 3. Effects of oestrogens and triphenylethylene compounds on the induction of implantation in delayed implanting mice. Numbers in parentheses represent the number of animals. Values within the bar indicate mean ( \pm s.e.m.) numbers of implantation sites of animals showing blue dye sites. All animals received progesterone $(2 \mathrm{mg} / \mathrm{mouse} /$ day). Abbreviations are as in Fig. 1 . 


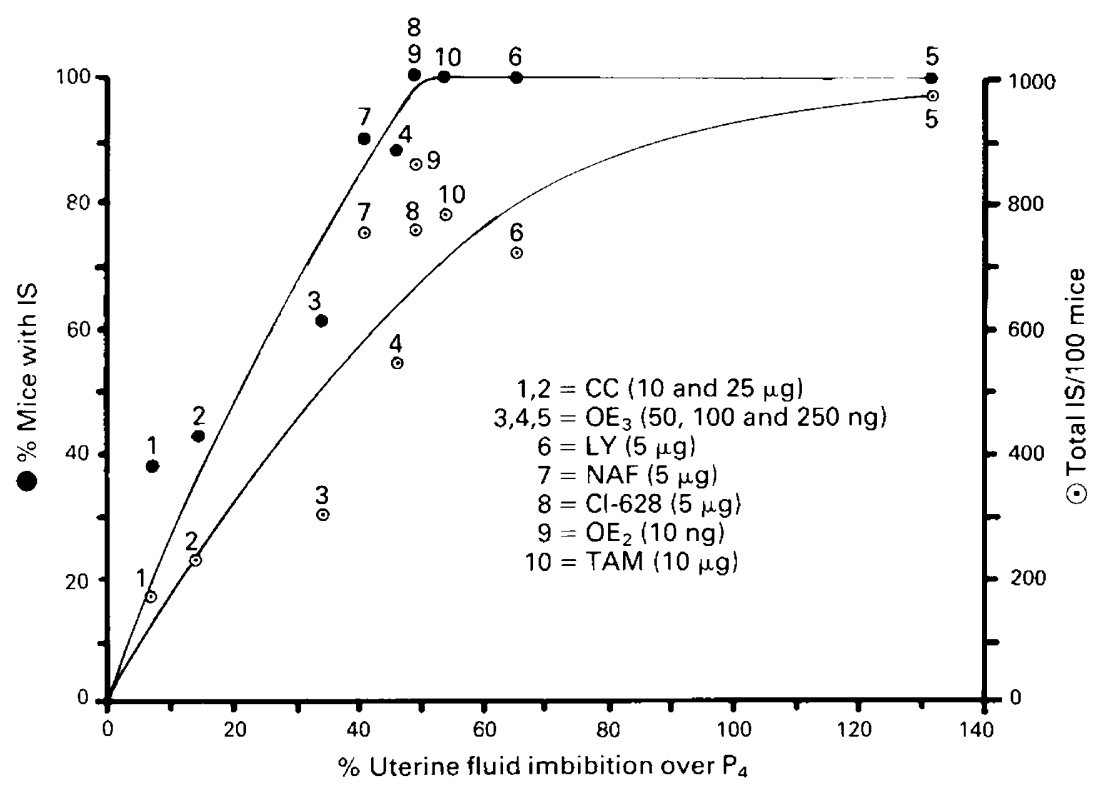

Fig. 4. Correlation between uterine fluid imbibition response and implantation after treatment with oestrogens and triphenylethylene compounds. The contents of this figure represent a composite illustration of the values of Figs 2 and 3. IS = implantation sites. Abbreviations are same as for Fig. 1.

the compounds tested, clomiphene citrate was the least effective in eliciting fluid imbibition at $6 \mathrm{~h}$ (a Phase I response) under the same conditions (Fig. 2) and also in initiating implantation in delayed implanting mice (Fig. 3). With increasing doses of oestriol from 50 to $250 \mathrm{ng}$ the percentage of mice with implantation sites increased to a full complement. The overall efficacy of the different compounds was measured by the proportion of animals with implantation and, better, by the total number of implantation sites in a same number of mice (Fig. 4). This reveals a strong correlation of this response with fluid imbibition under the same conditions. Although not shown, CI-628, nafoxidine and LY-117018 were effective in inducing implantation at dose ranges of 5-250 $\mu \mathrm{g}$, whereas tamoxifen was effective only at the dose shown here. Clomiphene citrate at doses above $(125 \mu \mathrm{g}$ and $250 \mu \mathrm{g}$ ) and below (1 $\mu \mathrm{g}$ ) those shown (Fig. 3) also had poor implantation-inducing abilities. Furthermore, neither LY-117018 nor CI-628 was able to inhibit oestrogen-induced implantation. LY-117018 (125 $\mu \mathrm{g}$ /mouse) injected $30 \mathrm{~min}$ before and $4 \mathrm{~h}$ after oestradiol-17 $\beta$ ( $10 \mathrm{ng} /$ mouse) resulted in implantation in $86 \%$ of the mice $(\mathrm{N}=7)$ with a mean $( \pm$ s.e.m.) of $8.3 \pm 0.9$ implantation sites. When given only $30 \mathrm{~min}$ before oestradiol-17 $\beta$, the same compound showed implantation in $100 \%$ of the mice $(\mathbf{N}=5)$ with a mean of $5.8 \pm 1.9$ implantation sites. Injection of CI-628 $(250 \mu \mathrm{g} /$ mouse) followed by oestradiol $-17 \beta(10 \mathrm{ng} / \mathrm{mouse}) 30 \mathrm{~min}$ later induced implantation in $100 \%$ of the mice $(n=7)$ with a mean number of implantation sites of $6 \cdot 1 \pm 1 \cdot 3$.

\section{Discussion}

In general multiple injections of test compounds are used in ovariectomized or immature rats and mice without progesterone priming for determining their oestrogenic or antagonistic responses in the uterus (Katzenellenbogen \& Ferguson, 1975; Clark et al., 1977; Gardner et al., 1978; Black \& Goode, 1980; Clark \& Markaverich, 1982). In the non-progesterone primed rodent uterus, oestradiol 
has been shown to possess characteristics of both Phase I and Phase II, while oestriol as a single injection, exhibits only the former (Clark et al., 1977; Kirkland et al., 1977; Harris \& Gorski, 1978; Galand et al., 1983). However, progesterone-priming of the uterus is an absolute requirement for oestrogen to initiate implantation (Yoshinaga \& Adams, 1966; McLaren, 1973; Psychoyos, 1973). It is therefore imperative that oestrogens or triphenylethylene compounds be administered as single injections in a progesterone-primed uterus in order to reveal their effects on implantation. Our attempt to determine the effect of triphenylethylene compounds or oestrogens on the two phases of oestrogenic responses in a progesterone-primed uterus demonstrates that compounds which induce implantation consistently showed an increase in fluid imbibition (a Phase I response) but not necessarily an increase in dry weight (a Phase II response) after $24 \mathrm{~h}$. Although shown to be oestrogenic in the adult mouse (see review by Clark \& Markaverich, 1982), the failure of clomiphene citrate to manifest a marked Phase I response correlates well with its poor ability to initiate implantation (Figs 2 \& 3). Oestriol, considered an impeded oestrogen, induced a Phase I response and implantation in a dose-dependent manner, again revealing correlation between these responses. These observations suggest that this phase is an essential component of oestrogenic responses in implantation.

The failure of clomiphene citrate, even at higher doses ( 125 and $250 \mu \mathrm{g})$, to initiate implantation could be related to its poor capacity for fluid imbibition, but some other as yet unknown, deficiency in this compound could be involved. Nevertheless, a deficiency in fluid imbibition perhaps could be used as a marker to predict ineffectiveness of compounds to initiate implantation. Although we cannot ascertain the exact reason for the failure of the higher dose of tamoxifen $(250 \mu \mathrm{g})$ to induce implantation, one possibility could be that it is embryotoxic at high levels. This interpretation is consistent with the recovery of low numbers of blastocysts $(3 \cdot 0 \pm 0 \cdot 7, n=5)$ at this dose level. Triphenylethylene compounds, because of their antioestrogenic properties, have been used widely to interrupt early pregnancy (Nelson et al., 1963; Sengupta et al., 1979). However, experiments, have not been designed to test whether their weak oestrogenicity was adequate to elicit implantation in the delayed implanting animal. In the light of our results, it would be inappropriate to term indiscriminately these compounds as antioestrogens.

The component(s) of Phase I effects that induces implantation and how this response is triggered by oestrogen are presently unknown. Because gene expression can occur very rapidly in the target cell in response to hormonal signals, we cannot predict whether Phase I responses involve transcriptional expression of oestrogen action, although it has been shown that not only is the implantation-inducing effect of oestradiol not blocked by actinomycin $\mathrm{D}$, but the latter alone can induce implantation in the absence of oestrogen (Finn \& Martin, 1974).

This research was supported by a grant from NIH (HD-12304). Y.M.H. is supported by an NSF Graduate Fellowship.

\section{References}

Astwood, E.B. (1939) Changes in the weight and water content of the uterus of the normal adult rat. Am.J. Physiol. 126, 162-170.

Black, L.J. \& Goode, R.L. (1980) Uterine bioassay of tamoxifen, trioxifene and a new estrogen antagonist (LYI17018) in rats and mice. Life Sciences 26, 1453-1458.

Clark, J.H. \& Markaverich, B.M. (1982) The agonisticantagonistic properties of clomiphene: A review. Pharmac. Ther. 15, 467-509.

Clark, J.H., Paszko, Z. \& Peck, E.J. Jr. (1977) Nuclear binding and retention of the receptor estrogen complex: Relation to the agonistic and antagonistic properties of estriol. Endocrinology 97, 1-12.

Finn, C.A. \& Martin, L. (1974) The control of implantation. J. Reprod. Fert. 39, 195-206.

Galand, P., Mairesse, N., Rooryck, J.G. \& Flandroy, L. (1983) Differential blockade of estrogen induced responses by the antiestrogen nafoxidine. J. Steroid Biochem. 9, 1259-1263.

Gardner, R.M., Kirkland, J.L. \& Stancel, G.M. (1978) Selective blockade of estrogen-induced uterine responses by the antiestrogen nafoxidine. Endocrinology 103, $1583-1589$. 
Harris, J. \& Gorski, J. (1978) Evidence for a discontinuous requirement for estrogen in stimulation of deoxyribonucleic acid synthesis in the immature rat uterus. Endocrinology 103, 204-245.

Katzenellenbogen, B.S. \& Ferguson, E.R. (1975) Antiestrogen action in the uterus: Biological ineffectiveness of nuclear bound estradiol after antiestrogen. Endocrinology 97, 1-12.

Kirkland, J.L., Gardner, R.N., Ireland, J.S. \& Stancel, G.M. (1977) The effect of hypophysectomy on the uterine response to estradiol. Endocrinology 101, 403-410.

McCormack, J.T. \& Greenwald, G.S. (1974) Progesterone and oestradiol-17 $\beta$ concentrations in the peripheral plasma during pregnancy in the mouse. J. Endocr. 62, - 101-107.

McLaren, A. (1973) Blastocyst activation. In The Regulation of Mammalian Reproduction, pp. 321-328. Eds S. J. Segal, R. Crozier, P. A. Corffman \& P. G. Condliffe. Charles C. Thomas III, Springfield.
Nelson, w.o., Davidson, O.W. \& Kenro, W. (1963) Studies on interference with zygote development and implantation. In Delayed Implantation, pp. 183-196, Ed. A. C. Enders. University of Chicago Press, Chicago.

Psychoyos, A. (1973) Endocrine control of egg implantation. In Handbook of Physiology, pp. 187-215. Eds R. O. Greep, E. G. Astwood \& S. R. Geiger. American Physiological Society, Washington, D.C.

Sengupta, J., Roy, S.K. \& Manchanda, S. K. (1979) Hormonal control of implantation: A possible role of lysosomal function in the embryo-uterus interaction. J. Steroid Biochem. 11, 729-744.

Yoshinaga, K. \& Adams, C.E. (1966) Delayed implantation in the spayed, progesterone-treated adult mouse. J. Reprod. Fert. 12, 593-595.

Received 30 March 1987 